\title{
Corrigendum to "Therapeutic Potential of Olfactory Ensheathing Cells and Mesenchymal Stem Cells in Spinal Cord Injuries"
}

\author{
Anna Zadroga, ${ }^{1}$ Katarzyna Jezierska-Woźniak, ${ }^{2}$ Joanna Czarzasta, ${ }^{1}$ Monika Barczewska, ${ }^{2}$ \\ Joanna Wojtkiewicz, ${ }^{1,3,4}$ and Wojciech Maksymowicz ${ }^{2}$ \\ ${ }^{1}$ Department of Pathophysiology, Faculty of Medical Sciences, University of Warmia and Mazury in Olsztyn, Olsztyn, Poland \\ ${ }^{2}$ Department of Neurology and Neurosurgery, Faculty of Medical Sciences, University of Warmia and Mazury in Olsztyn, \\ Olsztyn, Poland \\ ${ }^{3}$ Laboratory for Regenerative Medicine, Faculty of Medical Sciences, University of Warmia and Mazury, Olsztyn, Poland \\ ${ }^{4}$ Foundation for the Nerve Cells Regeneration, Olsztyn, Poland
}

Correspondence should be addressed to Joanna Wojtkiewicz; joanna.wojtkiewicz@uwm.edu.pl

Received 6 April 2017; Accepted 23 April 2017; Published 31 May 2017

Copyright ( 2017 Anna Zadroga et al. This is an open access article distributed under the Creative Commons Attribution License, which permits unrestricted use, distribution, and reproduction in any medium, provided the original work is properly cited.

In the article titled "Therapeutic Potential of Olfactory Ensheathing Cells and Mesenchymal Stem Cells in Spinal Cord Injuries" [1], the first and last names of five of the authors were reversed as Zadroga Anna, Jezierska-Woźniak Katarzyna, Czarzasta Joanna, Wojtkiewicz Joanna, and Maksymowicz Wojciech. The authors' names should have been written as Anna Zadroga, Katarzyna Jezierska-Woźniak, Joanna Czarzasta, Joanna Wojtkiewicz, and Wojciech Maksymowicz. The revised authors' list is shown above.

\section{Reference}

[1] A. Zadroga, K. Jezierska-Woźniak, J. Czarzasta, M. Barczewska, J. Wojtkiewicz, and W. Maksymowicz, "Therapeutic Potential of Olfactory Ensheathing Cells and Mesenchymal Stem Cells in Spinal Cord Injuries," Stem Cells International, vol. 2017, Article ID 3978595, 6 pages, 2017. 

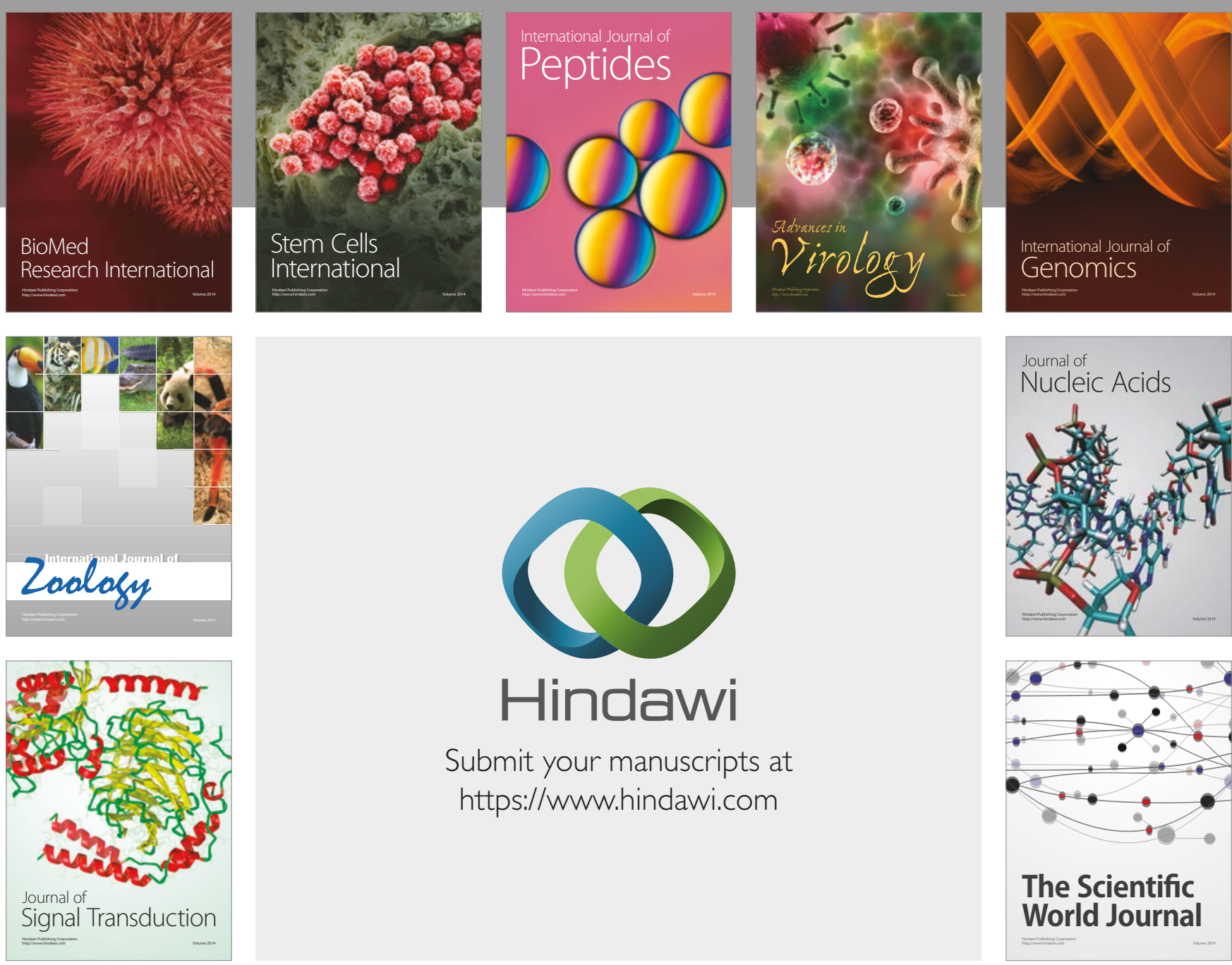

Submit your manuscripts at

https://www.hindawi.com
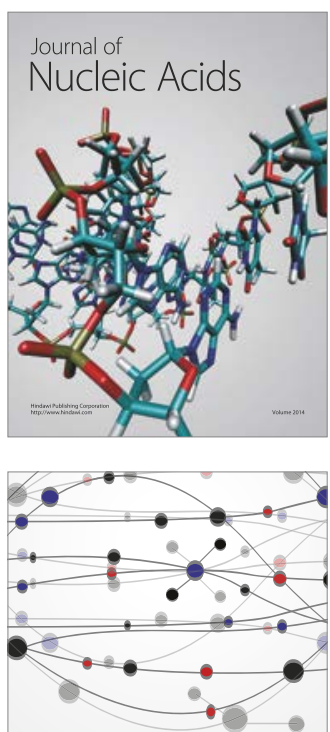

The Scientific World Journal

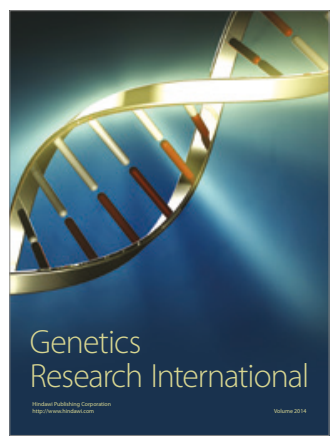

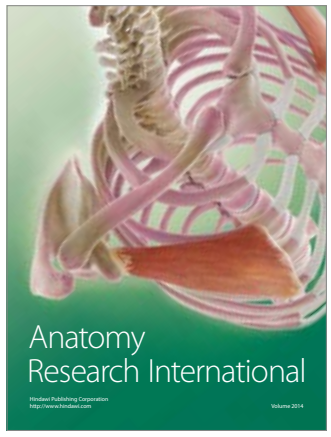

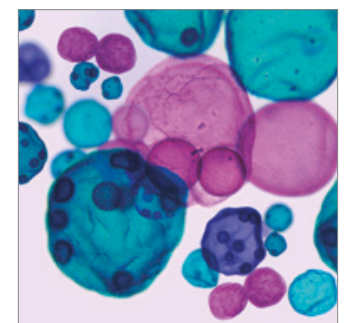

International Journal of Microbiology
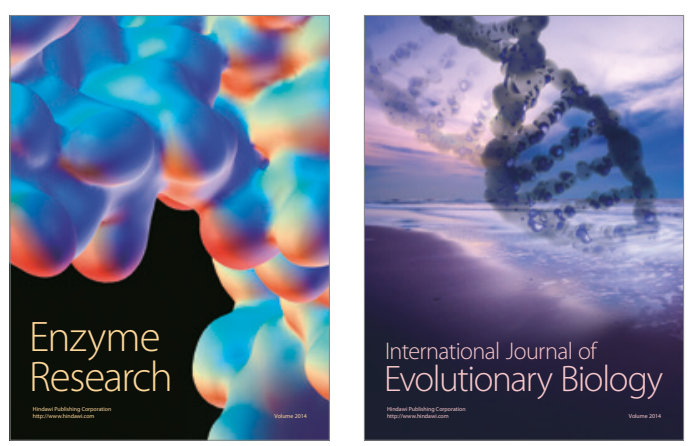
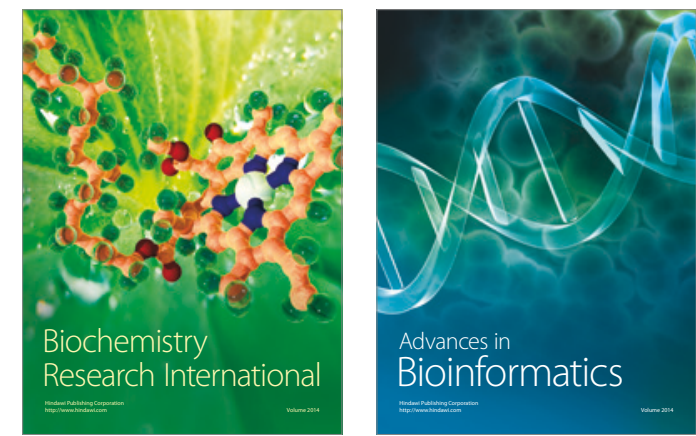

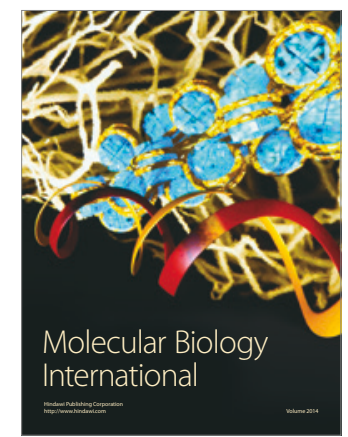

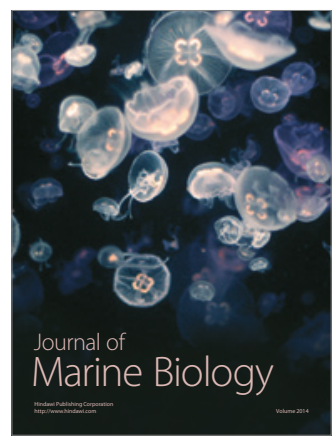

